\title{
Comparison of Posterior and Subcostal Ultrasound-Guided Transversus Abdominis Plane Block Approaches for Postoperative Analgesia in Laparoscopic Cholecystectomy
}

\author{
AHMED A. ABO ZAID, M.Sc.; MOHAMMAD A. EL-HARTY, M.D.; ASHRAF E. AL-ZEFTAWY, M.D. and \\ WAIL E. MESSBAH, M.D.
}

The Department of Anesthesiology and Surgical Intensive Care, Faculty of Medicine, Tanta University, Tanta, Egypt

\begin{abstract}
Background: Pain after LC is complex and characterized by various components with different intensities and time courses. The establishment of LC as an outpatient procedure has accentuated the clinical importance of proper post-operative pain control.
\end{abstract}

Aim: Our aim is to compare between US posterior and subcostal approaches TAP block for post-operative analgesia in LC.

Material and Methods: This study was carried out on 60 patients, ASA I-II, scheduled for elective laproscopic cholecystectomy under general anesthesia. Patients were randomized into three equal groups (20 patients in each group): Group I (control group): Received standard general anesthesia. Group II (posterior TAP group): Received standard general anesthesia and bilateral US guided posterior TAP block with $15 \mathrm{ml}$ bupivacaine $0.25 \%$ on each side just before extubation. Group III (subcostal TAP group): Received standard general anesthesia and bilateral US guided subcostal TAP block with $15 \mathrm{ml}$ bupivacaine $0.25 \%$ on each side just before extubation. All groups received post-operative analgesia in the form of IV paracetamol $1 \mathrm{gm}$ every 6 hours and rescue analgesic in form of morphine $2 \mathrm{mg}$ IV. The following parameters were compared: Post-operative vital signs (HR \& MAP), post-operative pain (using 10 point Visual Analogue Scale (VAS) where (0) no pain and (10) most intense pain), time for first post-operative required analgesia and 24-hour morphine consumption were measured in the 3 groups immediately after full recovery of anesthesia, 1h, 2h, 4h, 6h, 8h, 12hr \& $24 \mathrm{hr}$.

Results: In our study the mean values of HR and MAP were lower in Group II and Group III than Group I \& that of Group III were lower than that of Group II at all times after recovery. The mean values of pain assessment by VAS in Group II and Group III were lower than that of Group I at all times after recovery. The VAS in Group III were lower than that of Group II insignificantly immediately after recovery, $1 \mathrm{~h}, 2 \mathrm{~h}, 12 \mathrm{~h}$ and 24 hours and significantly at $4 \mathrm{~h}, 6 \mathrm{~h}$ and 8 hours. Also the mean time to the first request of morphine, was longer in Groups II and III than in Group I. Group III

Correspondence to: Dr. Ahmed A. Abo Zaid,

The Department of Anesthesiology and Surgical Intensive Care, Faculty of Medicine, Tanta University, Tanta, Egypt was significantly longer than Group II. The total dose of postoperative morphine consumption in Group II and Group III were lower than that in Group I. There was significantly lower total dose of post-operative morphine consumption in Group III than Group II.

Conclusion: Both the posterior and subcostal US TAP block provides superior analgesia than the standard IV regimen. However, beyond the initial 4 hours after recovery, patients in the subcostal TAP group had significantly lower pain scores than did patients from the other groups.

Key Words: Laparoscopic cholecystectomy (LC) - Ultrasound guided (US) - Posterior transversus abdominis plane (TAP) block - Subcostal transversus abdominis plane (TAP) block.

\section{Introduction}

ALTHOUGH Laparoscopic Cholecystectomy (LC) is performed on an ambulatory basis, it is not pain free. Post-operative pain in laparoscopic surgery is less severe compared to an open procedure, but is still considerable. The most effective pain relief can be obtained by combining opioids, local anesthetics, and NSAIDS into balanced analgesia. This approach at least allows the opioids dose to be reduced by the use of multimodal analgesia, thereby limiting side effects, reducing postoperative pain and analgesics, and facilitating an earlier return to normal activities [1,2].

In the last years, there has been growing interest in the use of peripheral regional anesthesia such as Transverses Abdominis Plane (TAP) blocks as an alternative to high-dose Intravenous (IV) analgesics for managing pain after abdominal surgeries [3-5].

The Transversus Abdominis Plane (TAP) block involves the sensory nerve supply of the anteriorlateral abdominal wall, where the T7-12 intercostal 
nerves, the ilioinguinal and iliohypogastric nerves, and the lateral cutaneous branches of the dorsal rami of L1-3 are blocked with an injection of local anesthetic between the Internal Oblique Abdominal Muscle (IOAM) and the Transversus Abdominus Muscle (TAM). More studies need to be conducted to provide conclusive evidence in favor of use of transversus abdominis plane block in LC [6].

The conventional method of giving a TAP block using ultrasound gauidance has been the posterior TAP block. The ultrasound probe is placed in a plane transverse to the lateral abdominal wall in the anterior axillary line, between the lower costal margin and iliac crest. At this site, the TAP is identified and the drug is injected by direct vision $[7,8]$.

Hebbard [9] described a new technique called the subcostal TAP block, which involves the use of ultrasound to deposit local anesthetic in a more cephalad position, with the probe being placed immediately inferior to the costal margin on the anterior abdominal wall. The drug is injected at this location, immediately lateral to the linea semilunaris in the TAP [10]

\section{Aim and objectives:}

The aim of this study is to compare between ultrasound guided posterior and subcostal approaches transversus abdominis plane block for postoperative analgesia in laproscopic cholecystectomy.

\section{Material and Methods}

This study was carried out in Tanta University Hospitals in General Surgery Department for eight months from February 2016 to September 2016 on 60 adult patients of both sex scheduled for elective laparoscopic cholecystectomy under general anesthesia with ASA physical status I or II. After approval from Institutional Ehics Committee, an informed conscent was taken from each patient. All data of patients was confidential with secret codes and private file for each patient, all given data was used for current medical research only. Any unexpected risks appearing through course of research were cleared to participients and Ethical Committee on time.

Exclusion criteria include: Patient refusal, history of allergy to local anesthetics, local infection, patients with coagulopathies and impaired platelet function.

Patients was randomly classified using sealed envelope into three equal groups each of $20 \mathrm{pa}-$ tients. Group I (control) received standard general anesthesia, Group II (posterior TAP) received standered general anesthesia as in Group I and bilateral US guided posterior TAP block with $15 \mathrm{ml}$ bupivacaine $0.25 \%$ on each side just before extubation and Group III (subcostal TAP) received standered general anesthesia as in Group I \& II and bilateral US guided subcostal TAP block with $15 \mathrm{ml}$ bupivacaine $0.25 \%$ on each side just before extubation. The three groups received postoperative analgesia in the form of IV paracetamol $1 \mathrm{gm}$ every 6 hours and rescue analgesic in form of morphine $2 \mathrm{mg}$ IV.

\section{Anesthetic technique:}

- Pre-operative:

Medical and surgical histories of the patient was evaluated, clinical examination of the patient was performed, routine laboratory investigations was evaluated including complete blood picture, prothrombin time and activity.

\section{-Intraoperative:}

Routine monitoring of heart rate by ECG, NonInvasive Blood Pressure (NIBP) including systolic, diastolic and mean arterial blood pressure, oxygen saturation (SPO 2) using pulse oxymeter was performed, an Intravenous (I.V) line was established with an $18 \mathrm{G}$ cannula.

General anesthesia was induced IV using $2 \mathrm{gg} / \mathrm{kg}$ of fentanyl and $2.0 \mathrm{mg} / \mathrm{kg}$ of propofol. Tracheal intubation was facilitated by $0.15 \mathrm{mg} / \mathrm{kg}$ cisatracurium and muscle relaxation was maintained with additional doses $0.02 \mathrm{mg} / \mathrm{kg}$. An orogastric tube was inserted, and anesthesia was maintained with isoflurane MAC 1.5. Intraoperative monitoring will include electrocardiography, pulse oximetry, non-invasive blood pressure, end-tidal carbon dioxide concentration ( $\mathrm{EtCO} 2)$.

Isoflurane concentration was adjusted to maintain the Mean Arterial Pressure (MAP) within 20\% of the pre-induction value.

Intra-abdominal pressure was limited to 14 $\mathrm{mmHg}$, and minute ventilation was adjusted to maintain $\mathrm{EtCO}_{2}$ between 35 and $40 \mathrm{mmHg}$.

At the end of surgery, the inflated carbon dioxide was carefully evacuated by manual compression of the abdomen and residual neuromuscular blockade was antagonized with neostigmine $0.05 \mathrm{mg} / \mathrm{kg}$ and atropine $0.01 \mathrm{mg} / \mathrm{kg}$.

\section{Technique of posterior TAP block:}

A high-frequency $(5-10 \mathrm{MHz})$ ultrasound probe was placed transversely along the anterolateral 
abdominal wall on one side at the level of the anterior axillary line, between the iliac crest and the subcostal margin, to identify the external oblique, internal oblique, and transversus abdominis muscles. After identification of the neurofascial plane between the internal oblique and the transversus abdominis muscle, A 23-gauge (G) spinal needle was introduced anteriorly in the plane of the ultrasound beam and directed towards this plane. Once the tip of the needle was placed in the space between the IOM and TAM and negative aspiration was done, $15 \mathrm{ml}$ bupivacaine $0.25 \%$ was administrated under direct US guidance on each side.

\section{Technique of subcostal TAP block:}

A high-frequency $(5-10 \mathrm{MHz})$ ultrasound probe was placed in the midline of the abdomen $2 \mathrm{~cm}$ below the xiphisternum and was moved laterally along the subcostal margin to the anterior axillary line. The transversus abdominis muscle was identified lying beneath and extending lateral to the rectus abdominis muscle. A 23-gauge $(\mathrm{G})$ spinal needle was then guided, in plane, to a point just inferior to the costal margin at the anterior axillary line such that the tip lay between the transversus abdominis and internal oblique muscle within the neurovascular fascial plane. Once the tip of the needle was placed in the space between the IOM and TAM and negative aspiration was done, $15 \mathrm{ml}$ bupivacaine $0.25 \%$ will be administrated under direct US guidance on each side.

\section{The following data was recorded:}

1- Vital signs (heart rate \& MAP) were recorded immediately after full recovery then at $1,2,4$, 6, 8, 12 and 24 hours post-operatively.

2- Post-operative Visual Analogue Score (VAS) was recorded immediately after full recovery and at 1, 2, 4, 6, 8, 12 and 24 hours postoperatively.

- VAS 0-3: Mild pain.

- VAS 4-6: Moderate pain.

- VAS more than 6: Severe pain.

Patients with VAS score more than 4 received rescue analgesic in form of morphine $2 \mathrm{mg}$ IV with total dose not more than $6 \mathrm{mg}$ per hour.

3- Time for first post-operative analgesia required was recorded.

4- 24-hour morphine consumption was recorded.

5- Post-operative complications during first 24 hours.
The sample size calculation is performed using EpI-Info 2002 software statistical package designed by World Health Organization (WHO) and by Centers for Disease Control and Prevention (CDC). The sample size is calculated as $\mathrm{N}>18$ with $10 \%$ variation based on the following considerations: 95\% confidence limit, $80 \%$ power of the study.

Statistical presentation and analysis was conductedby SPSS V.24. Results were expressed as means \pm Standard Deviation (SD).Student paired $t$-test: For statistical analysis within the same group.Unpaired $t$-test: Used for comparison of parametric data between the three studied groups. Modified chi-square test for small numbers: For comparison between three groups as regards qualitative data. ANOVA test was used for comparison among different times in the same group in quantitative data. $p$-value $<0.05$ was considered significant.

\section{Results}

There was no significant difference between the three groups as regard to age, weight and duration of surgery.

In our study the mean values of heart rate and mean arterial blood pressure were lower in Group II and Group III compared to Group I significantly immediately after recovery, $1 \mathrm{~h} \& 2 \mathrm{~h}$ and insignificantly at $4 \mathrm{~h}, 6 \mathrm{~h}, 8 \mathrm{~h}, 12 \mathrm{~h}$ and $24 \mathrm{~h}$. The mean values of heart rate and mean arterial blood pressure of Group III were lower than that of Group II insignificantly immediatly after recovery, at $1 \mathrm{~h}$ and 2 hours and significantly at $4 \mathrm{~h}, 6 \mathrm{~h}, 8 \mathrm{~h}, 12 \mathrm{~h}$ and 24 hours after recovery.

The mean values of pain assessment by VAS in Group II were lower than that of Group I significantly immediatly after recovery, $1 \mathrm{~h}$ and 2 hours and insignificantly at $4 \mathrm{~h}, 6 \mathrm{~h}, 8 \mathrm{~h}, 12 \mathrm{~h}$ and 24 hours after recovery. Also the mean values of pain assessment by VAS in of Group III were lower than that of Group I significantly immediatly after recovery, $2 \mathrm{~h}, 4 \mathrm{~h}, 6 \mathrm{~h}, 8 \mathrm{~h}, 12 \mathrm{~h}$ and 24 hours after recovery. The mean values of pain assessment by VAS in Group III were lower than that of Group II insignificantly immediately after recovery, $1 \mathrm{~h}$, $2 \mathrm{~h}, 12 \mathrm{~h}$ and 24 hours and significantly at $4 \mathrm{~h}, 6 \mathrm{~h}$ and 8 hours.

Also we found that the mean time to the first request of morphine, was longer in Groups II and III than in Group I. Group III was significantly longer than Group II. The total dose of postoperative morphine consumption in Group II and Group III were lower than that in Group I. There was 
significantly lower total dose of post-operative morphine consumption in Group III than Group II.

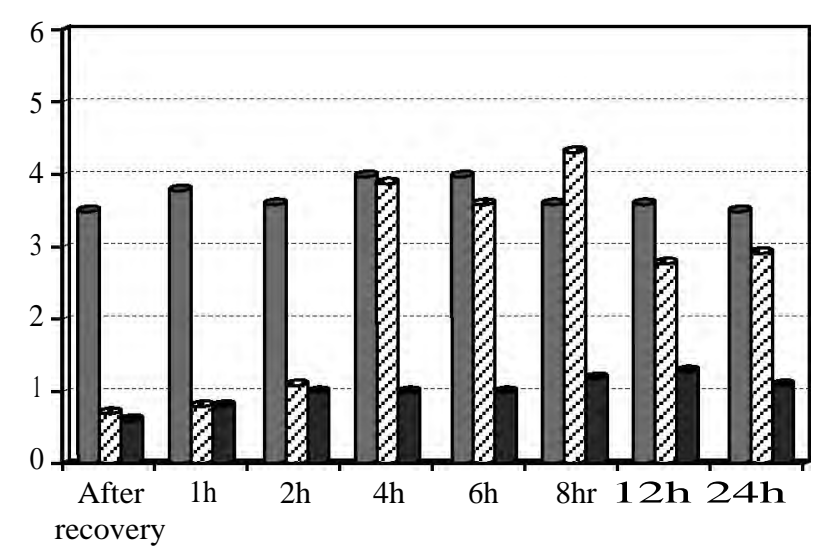

Fig. (1): Comparison of mean of pain assessment by VAS between three groups.

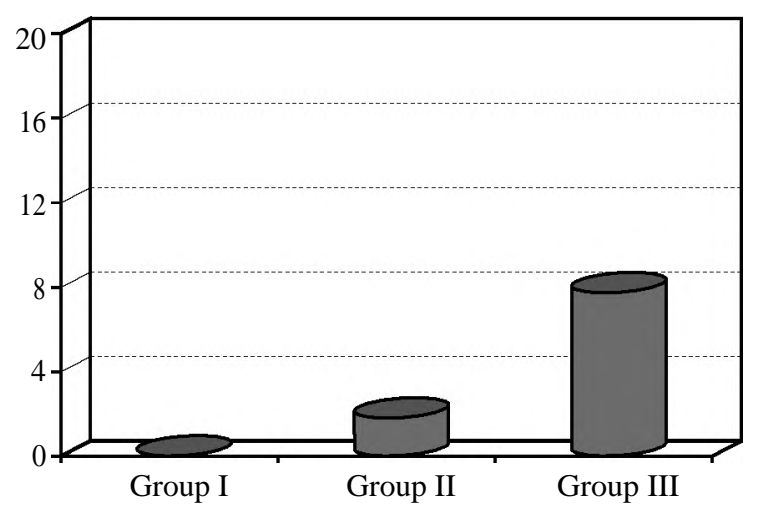

Fig. (2): Comparison of mean time to first request of analgesia between the three groups (hour).

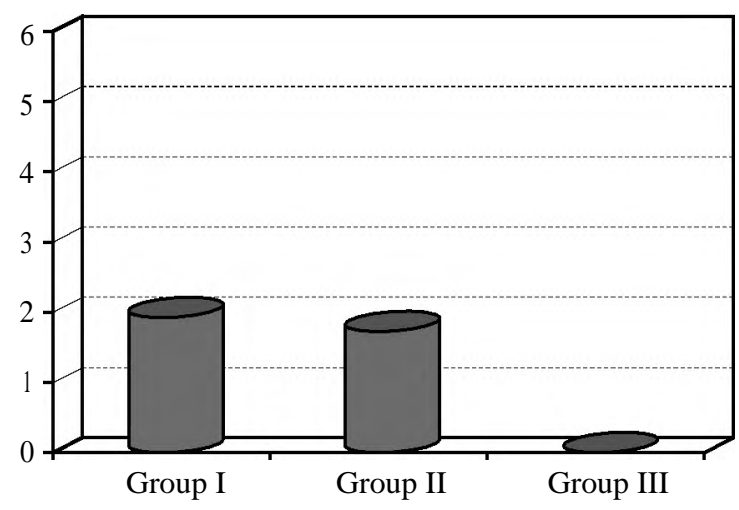

Fig. (3): Comparison of mean value of post-operative morphine dose consumption ( $\mathrm{mg}$ ) between the three groups.

\section{Discussion}

Despite all the benefits that have emerged with the introduction of laparscopic surgery, postoperative pain remains an issue. Ineffectively treated post-operative pain is still one of the com- mon problems that may result in clinical and psychological changes which increase morbidity and mortality as well as costs and may decrease the quality of life. Prevention and effective relief of acute pain may improve clinical outcomes, avoid clinical complications, save health care resources, and improve quality of life [11].

The Transverses Abdominus Plane (TAP) block is a regional analgesic technique which has an evolving role in post-operative analgesia for abdominal surgeries [12-14]. It is a simple and safe technique and is a potential alterative to opioid for analgesia after LC, whether guided by traditional anatomic landmarks or better by ultrasound which has two approaches: Posterior and subcostal approach $[\mathbf{1 5 , 1 6}$.

As regard to post-operative hemodynamic changes, our result showed that the mean values of heart rate and mean arterial blood pressure were lower in Group II and Group III compared to Group I significantly immediately after recovery, $1 \mathrm{~h} \&$ $2 \mathrm{~h}$ and insignificantly at $4 \mathrm{~h}, 6 \mathrm{~h}, 8 \mathrm{~h}, 12 \mathrm{~h}$ and $24 \mathrm{~h}$. The mean values of heart rate and mean arterial blood pressure of Group III were lower than that of Group II insignificantly immediatly after recovery, at $1 \mathrm{~h}$ and 2 hours and significantly at $4 \mathrm{~h}, 6 \mathrm{~h}$, $8 \mathrm{~h}, 12 \mathrm{~h}$ and 24 hours after recovery.

This may be due to analgesic effect of TAP block that reduces pain intensity which stimulate sympathetic system and cause increasing in heart rate and mean arterial blood pressure of the patient.

Our results are in agreement with Niraj G et al., [17] who compared the analgesic efficacy of subcostal TAP blocks with epidural analgesia following upper abdominal surgery. They found that TAP blocks have minimal hemodynamic effects, making them an acceptable technique for the hypotensive patients. The motor and sensory functions of the lower limbs are spared and the technique is non sedating, resulting in earlier ambulation following abdominal surgery [17]

Also our results are in agreement with Sulagna B et al., [18] who conducted their study on 90 adult female patients ASA I or II were randomized to Group B receiving TAP block with $0.25 \%$ bupivacaine and Group $\mathrm{N}$ with normal saline followed by general anaesthesia. Hemodynamic responses to surgical incision and intraoperative fentanyl consumption were noted. They found that preincisional TAP block decreases intraoperative fentanyl requirements, prevents hemodynamic responses to surgical stimuli and provides effective postoperative analgesia [18]. 
As regard to post-operative analgesia in this study, it was evaluated by using VAS (primary outcome), the mean values of pain assessment by VAS in Group II were lower than that of Group I significantly immediatly after recovery, $1 \mathrm{~h}$ and 2 hours and insignificantly at $4 \mathrm{~h}, 6 \mathrm{~h}, 8 \mathrm{~h}, 12 \mathrm{~h}$ and 24 hours after recovery. Also the mean values of pain assessment by VAS in of Group III were lower than that of Group I significantly immediatly after recovery, $2 \mathrm{~h}, 4 \mathrm{~h}, 6 \mathrm{~h}, 8 \mathrm{~h}, 12 \mathrm{~h}$ and 24 hours after recovery. The mean values of pain assessment by VAS in Group III were lower than that of Group II insignificantly immediately after recovery, $1 \mathrm{~h}$, $2 \mathrm{~h}, 12 \mathrm{~h}$ and 24 hours and significantly at $4 \mathrm{~h}, 6 \mathrm{~h}$ and 8 hours.

Also we found that the mean time to the first request of morphine (secondary outcome), was longer in Groups II and III than in Group I. Group III was significantly longer than Group II. The total dose of post-operative morphine consumption in Group II and Group III were lower than that in Group I. There was significantly lower total dose of post-operative morphine consumption in Group III than Group II.

This may be due to the effect of TAP in blocking the sensory afferent nerves that supply the anterior abdominal wall including the skin, muscles, and parietal peritoneum.

In agreement with us, Laleh Eslamian [19] who performed TAP block with $30 \mathrm{ml} 0.25 \%$ bupivacaine in a group and no TAP in the other group, they found that there was a significantly longer time to the first request for analgesic in the TAP block group [210 min vs. $30 \mathrm{~min}$ in no TAP block group, and women in TAP block group had significantly less Tramadol than women in no TAP block group (50mg vs. $25 \mathrm{mg}$ ).

In our study we use $15 \mathrm{ml}$ bupivacaine $0.25 \%$ on each side as local anaesthetic and morphine as a rescue analgesia.

Similar results were found by Hebbard et al., [20] have shown the efficacy of TAP blocks in the reduction of post-operative pain intensity and analgesic requirement in patients who undergo radical prostatectomy, hysterectomy, Cesarean delivery, and laparoscopic surgery. In one study, blockade with $1.5 \mathrm{mg} / \mathrm{kg}$ ropivacaine bilaterally in cesarean delivery parturients successfully decreased the post-operative patient-controlled IV morphine requirement. The authors of this study found that the TAP block was effective for 36h [20].
The possibility that the TAP region is relatively poorly vascularized was considered as a reason for this prolonged blockade.

In agreement with us Bhatia et al., [21] who conducted their study on 60 patients were they randomized into three groups of 20 patients each. Group 1 patients received standard general anesthesia (control group); Group 2 patients received an ultrasound-guided posterior TAP block using $15 \mathrm{~mL}$ of $0.375 \%$ ropivacaine on each side; and Group 3 patients underwent a subcostal TAP block with $15 \mathrm{~mL}$ of $0.375 \%$ ropivacaine on each side. The presence and severity of pain during rest and movement, as well as nausea or vomiting and sedation, were assessed in all patients post-operatively on PACU admission, then at 2, 4, 6, 8, 12, and 24hour intervals. Patients with a Visual Analog Score (VAS) greater than 4 , or those requesting analgesic were given intravenous tramadol $2 \mathrm{mg} / \mathrm{kg}$ as an initial dose; subsequent $1 \mathrm{mg} / \mathrm{kg}$ doses of tramadol, if needed, were given.

Patients who received a subcostal TAP block had significantly lower pain scores at rest and on movement than the control group at all times postoperatively. Although, in the initial post-operative measurement times, the subcostal and posterior TAP groups had comparable pain scores, after 4 hours these scores were significantly lower in patients who had received the subcostal TAP block [21].

But in our study we used $15 \mathrm{ml}$ bupivacaine $0.25 \%$ on each side as local anaesthetic and morphine as a rescue analgesia.

In agreement to our results McDonnell et al., [22] who performed TAP block with ropivacaine $(150 \mathrm{mg})$ vs placepo in addition to PCA morphine, diclofinac and acetaminophen after spinal anaesthesia, proved that the first request for analgesia in patients who did not have TAP was after 90 minutes, while in patients who received land mark TAP block, it was after 220 minutes [22].

In our study we use bupivacaine as local anaesthetic which is more potent than ropivacaine that may be the cause of less prolonged time of analgesia in TAP block group in McDonnell and curley study in comparison with our study.

Another study of McDonnell et al., [22] proved that TAP block reduced total morphine consumption in first 48 hours post-operatively ( $66 \pm 26$ vs $18 \pm 4 \mathrm{mg}$ ). The reason for less morphine consumption in this study is the use of multimodal analgesic drugs plus the use of spinal anaesthesia and high 
concentration of local anaesthetic in the TAP block groups but in our study we use only morphine as a rescue analgesic, also the study period is different [22].

Kelly et al., [23] proved that TAP blocks have been shown to offer improved pain relief after cesarean sections when compared to a placebo, but have been shown to be inferior to subarachnoid morphine.

In conssestant with our results Andrey [24] demonstrates the analgesic effectiveness of both Paravertebral Block (PVB) and TAP block after major gynecological cancer surgery. Both regional anaesthetic techniques demonstrated significant reductions in both opioid requirements and pain scores during early and late post-operative periods [24].

The results of this study support previous findings that TAP block performed preoperatively provides sufficient and long-lasting analgesia.

Hyun-Jung et al., [25] proved that US-TAP block with standard care provieds more effective analgesia after gynecological surgery, their study was conducted on 32 patient randomized to undergo gynecological surgery with postoperative standard care such as PCA or to receive US-TAP block with standard care after general anaesthesia induction, bilateral US-TAP wasperformed using $0.375 \%$ ropivacaine $20 \mathrm{ml}$ on each side, the pain score was significantly lower in the US-TAP group [25]

H-Loane [26] disagreed with us in which TAP block was associated with greater supplemental morphine requirements than intrathecal morphine (7.5mg vs $2.7 \mathrm{mg}$ ) in 24 hours, this study was conducted on 66 women undergoing elective caesarean delivery under spinal anesthesia, they were randomized to receive either intrathecal morphine 100 microgram plus TAP or a TAP block with $0.5 \%$ ropivacaine $1.5 \mathrm{mg} / \mathrm{kg}$ to each side [26]

The disagreement most probably due to the use of morphine intrathecaly which increases the duration of analgesia.

Also in disagreement with our results, Puddy E et al., [27] who conducted their study on 48 elective caesarean section parturients who were randomly assigned to undergo TAP block with either bupivacaine $(n=23)$ or saline $(n=25)$. All patients received a spinal anaesthetic with $0.5 \%$ heavy bupivacaine and $300 \mu \mathrm{g}$ diamorphine. All patients received a loading dose of rectal diclofenac and paracetamol. Standard post-operative analgesia comprised regular diclofenac and paracetamol, and subcutaneous morphine on request. A blinded investigator assessed each patient post-operatively $2,6,24$ and $48 \mathrm{~h}$ post-operatively. There were no statistically significant differences in post-operative morphine requirement or visual analogue pain scores between the two groups [27].

However, their study were performed on parturients who underwent spinal anesthesia and intrathecal diamorphine was used. It seems that the design of these study mainly differed from ours.

Also in disagreement with our results, Costello et al., [16] who conducted their study on 100 women undergoing elective $\mathrm{CD}$ under spinal anesthesia. Patients were randomized to receive the TAP block with ropivacaine $(n=50)$ or placebo $(n=50)$, in addition to a standard post-operative analgesic regimen inclusive of intrathecal opioids. Each patient was assessed at $6,12,24$, and $48 \mathrm{hrs}$ postoperatively. They found that the mean (SD) visual analog scale pain scores on movement at $24 \mathrm{hrs}$ were not different between the ropivacaine and placebo groups the pain scores at other times, and the supplemental opioid consumption, were also similar between the 2 groups [16]

However, their study were performed on parturients who underwent spinal anesthesia which differed from our design.

Also in disagreement with our results, Ortiz et al., [28] who conducted their study on eighty patients undergoing laparoscopic cholecystectomy were randomized to receive either bilateral TAP blocks or local anesthetic infiltration of trocar insertion sites with ropivacaine $0.5 \%$. Postoperative pain scores and analgesic use for the first $24 \mathrm{hrs}$ were recorded. They found that no statistically significant difference in pain scores on the numeric analog scale $(0-10)$ between the groups at $4 \mathrm{hrs}$ after surgery or during the $24 \mathrm{hrs}$ after surgery [28].

As regard to post-operative nausea and vomiting, our results showed that its incidence was lower in Group II and Group III than Group I but it didn't reach significant values.

Also our results are in agreement with Carney et al., [29] who conducted their study on 15 females undergoing total abdominal hysterectomy. Patients were randomized into groups to undergo TAP vs placebo in addition to PCA morphine, diclofinac and acetaminophen post-operatively. They found that there was no significant difference in the incidence or severity of nausea between groups at any time point [29] 


\section{Conclusion:}

We can conclude from this study that in patients undergoing laparoscopic cholecystectomy both the posterior and subcostal ultrasound-guided transversus abdominis block provides superior analgesia than the standard IV regimen. However, beyond the initial 4 hours after recovery, patients in the subcostal TAP group had significantly lower pain scores than did patients from the other groups.

So, for incisions mainly involving the supraumbilical region, subcostal TAP block may be a better alternative than the posterior approach for providing post-operative analgesia as acomponent of a multimodal analgesic technique.

\section{Conflicts of interest:}

No conflicts of interest declared.

\section{Authors' contributions:}

All authors had equal role in design, work, statistical analysis and manuscript writing.

\section{References}

1- BEAULIEU P.: Non-opioid strategies for acute pain management. Can. J. Anesth., 54: 481-5, 2007.

2- ANDERS MELLER, DONATSKY, FLEMMING BJERRUM, et al.: Intraperitoneal instillation of saline and local anesthesia for prevention of shoulder pain after laparoscopic cholecy-stectomy: A systematic review. Surg. Endosc., 27: 2283-92, 2013.

3- KUPPUVELUMANI P., JARADI H. and DELILKAN A.: Abdominal nerve blockade for post-operative analgesia after caesarean section. Asia Oceania J. Obstet. Gynaecol., 19: 165-9, 1993.

4- CARNEY J., McDONNELL J.G., OCHANA A., et al.: The transversus abdominis plane block provides effective post-operative analgesia in patients undergoing total abdominal hysterectomy. Anesth. Analg., 107: 2056-60, 2008.

5- BAHATIA N., ARORA S., WEG J., et al.: Comparison of posterior and subcostal approaches to ultrasound-guided transverse abdominis plane block for post-operative analgesia in laparoscopic cholecystectomy. J. of Anesthesia, 80-812, 2014.

6- EL-DAWLATLY A., TURKISTANI A., KETTNER S.C., et al.: Ultrasound-guided transverse abdominis plane block: Description of a new technique and comparison with conventional systemic analgesia during laparoscopic cholecystectomy. Br. J. Anaesth., 102: 763-7, 2009.

7- HEBBARD P., FUJIWARA Y., SHIBATA Y., et al.: Ultrasound-guided Transversus Abdominis Plane (TAP) block. Anaesth Intensive Care; 35: 616-7, 2007. Trujillo K.A., Smith M.L., Sullivan B., Heller C.Y., Garcia C., Bates M.: The neurobehavioral pharmacology of ketamine: Implications for drug abuse, addiction, and psychiatric disorders. ILAR Journal, 52 (3): 366-78, 2011.

8- WALTER E.J., SMITH P., ALBERTYN R., et al.: Ultra- sound imaging for transversus abdominis blocks. Anaesthesia, 63: 211, 2008.

9- HEBBARD P.: Subcostal transversus abdominis plane block under ultrasound guidance. Anesth. Analg., 106: 674-5, 2008.

10- LEE T.H., BARRINGTON M.J., TRAN T.M., et al.: Comparison of extent of sensory block following posterior and subcostal approaches to ultrasound-guided transversus abdominis plane block. Anaesth. Intensive Care, 38: 45260, 2010.

11- MENTES O., HARLAK A., YIGIT T., et al.: Effect of intraoperative magnesium sulphate infusion on pain relief after laparoscopic cholecystectomy. Acta Anaesthesiol. Scand., 52: 1353-9, 2008. Kim H.K., Yoon K.C., Park Y.G.: Oculocardiac reflex during strabismus surgery. Journal of the Korean Ophthalmological Society, 44 (4): 896-903, 2003.

12- MARHOFER P., HARROP G.W., WILLSCHKE H., et al.: Fifteen years of ultrasound guidance in regional anaesthesia: Part 2-recent developments in block techniques. Br. J. Anaesth., 104: 673-83, 2010. Safavi M., Honarmand A.: Comparison of effects of thiopental, propofol or ketamine on the cardiovascular responses of the oculocardiac reflex during strabismus surgery. Journal of Research in Medical Sciences, 12 (5): 246-50, 2007.

13- BONNET F., BERGER J. and AVELINE C.: Transversus abdominis plane block: What is its role in post-operative analgesia? Br. J. Anaesth., 103: 468-70, 2009.

14- PETERSEN P.L., MATHIESEN O., TORUP H., et al.: The transversus abdominis plane block: A valuable option for post-operative analgesia? A topical review. Acta Anaesthesiologica Scandinavica, 54 (5): 529-35, 2010.

15- BELAVY D., COWLISHAW P.J., HOWES M., et al.: Ultrasound-guided transversusabdominis plane block for analgesia after Caesarean delivery. Br. J. Anaesth., 103: 726-30, 2009.

16- COSTELLO J.F., MOORE A.R., WIECZOREK P.M., et al.: The transversus abdominis plane block, when used as part of a multimodal regimen inclusive of intrathecal morphine, does not improve analgesia after Cesarean delivery. Reg. Anesth. Pain Med., 34: 586-9, 2009.

17- NIRAJ G., KELKAR A., GRAFF-BAKER P., et al.: Comparison of analgesic efficacy of subcostal transversus abdominis plane blocks with epidural analgesia following upper abdominal surgery. Anaesthesia, 66 (6): 465-71, 2011.

18- SULAGNA B., MANJUSHREE R., TAPAS G., et al.: Analgesic efficacy of transversus abdominis plane block in providing effective perioperative analgesia in patients undergoing total abdominal hysterectomy: A randomized controlle trial, 30: 391-6, 2014

19- LALEH E.: Transversus abdominis plane block reduces post-operative pain intensity and analgesic consumption in elective cesarean delivery under general anesthesia. J. Anaesth., 26: 333-8, 2012.

20- HEBBARD P.D. and BARRINGTON M.J.: Ultrasoundguided continuous oblique subcostal transversus abdominis plane blockade: Description of anatomy and clinical technique. Regional anesthesia and pain medicine, 35 (5): 436-41, 2010. 
21- BHATIA N., ARORA S., KAUR G., et al.: Comparison of posterior and subcostal approaches to ultrasound-guided transverse abdominis plane block for post-operative analgesia in laparoscopic cholecystectomy. " Journal of clinical anesth-esia 26. 4: 294-29, 2014.

22- McDONNELL J.G. and CURLEY G.: The analgesic efficacy of transversus abdominis plane block after cesarean delivery: A randomized controlled trial. Anaesth Analg., 106: 186-91, 2008. St. Pierre M., Kessebohm K., Schmid M., Kundt H., Hering W., Recovery from anaesthesia and incidence and intensity of postoperative nausea and vomiting following a total intravenous anaesthesia (TIVA) with S-(+)-ketamine/propofol compared to alfentanil/propofol. Der. Anaesthesist., 51 (12): 973-9, 2002.

23- KELLY S. M.C. and MALHOTRA R.K.: Ultrasoundguided transversus abdominis plane blocks for analgesia post cesarean section. 1: 35-8. Thorp A.W., Brown L. and Green S.M. Ketamine-associated vomiting: Is it doserelated? Pediatric Emergency Care, 2009, 25 (1): 15-8, 2011.

24- ANDREY L.M.: Thoracic paravertebral block versus transversus abdominis plane block in major gynecological surgery: A prospective, randomized, controlled study, 5: 55-61, 2012.
25- HYUN-JUNG S.: Preemptive analgesic efficacy of ultrasound-guided transversus abdominis plane block in patients undergoing gynecologic surgery via a transverse lower abdominal skin incision, Korean J. Anaesthesiol., 61 (5): 413-8, 2001.

26- LOANE F.: A randomized controlled trial comparing intrathecal morphine with transversus abdominis plane block for postcesarean delivery analgesia, International Journal of Obstetric Anaesthesia, 21: 112-8, 2012.

27- PUDDY E. and EDWARDS B.: Does the Transversus Abdominis Plane (TAP) block improve analgesia following subarachnoid anesthesia with intrathecal diamorphine? A randomized double blinded control trial. Anaesthesia, 65-95, 2010.

28- ORTIZ J., SULIBURK J.W., BAILARD N.S., et al.: Bilateral transversus abdominis plane block does not decrease post-operative pain after laparoscopic cholecystectomy when compared with local anesthetic infiltration of trocar insertion sites. Regional anesthesia and pain medicine, 37 (2): 188-92, 2012.

29- CARNEY J.J. and McDONNELL J.G.: The transversus abdominis plane block provides effective post-operative analgesia in patients undergoing total abdominal hysterectomy. Anaesth. Analg., 107: 2056-60, 2008.

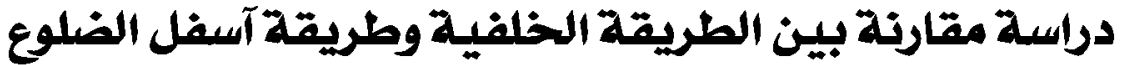

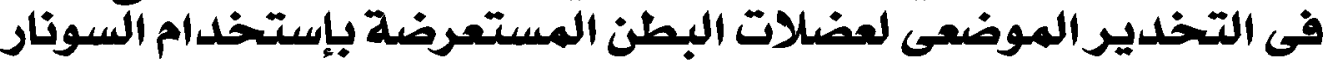

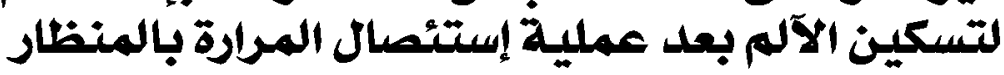

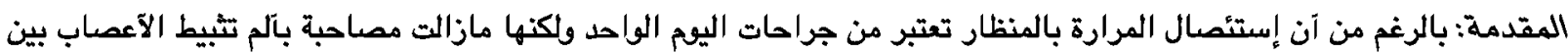

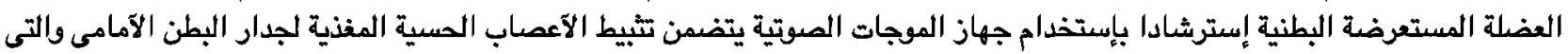

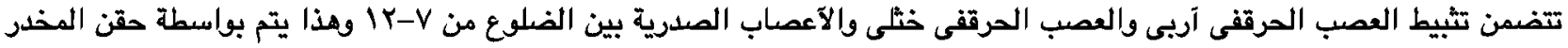

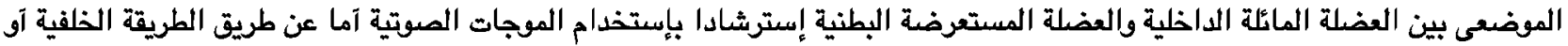
طريقة آسفل الضلوع.

الهدف من البحث:دراسة مقارنة بين الطريقة الخلفية وطريقة آسفل الضلوع فى التخدير الموضعى لعضلات البطن المستعرضة بإستخدام السونار لتسكين الآلم بعد عملية إستئصال المرارة بالمنظة مئهار.

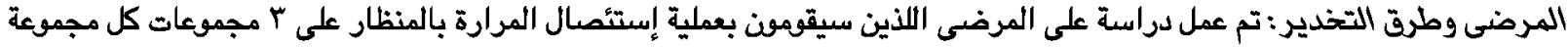

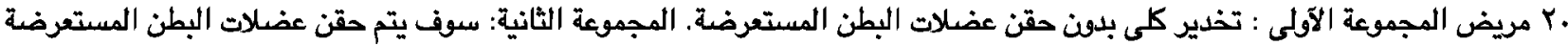

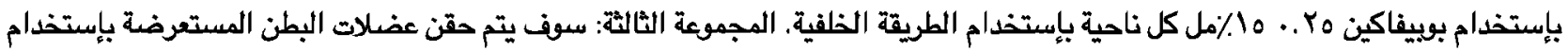

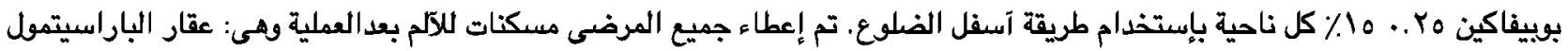

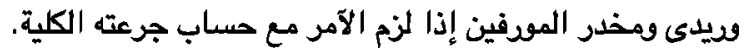

تم تسجيل القياسـات التالية: الوظائف الحيوية مثل النبض ومتوسط ضغط الدم ودرجة الآلم بإستخدام معامل قياس الآلم وضقت إعطاء المسكنات لآول مرة والجرعة الكلية لمخدر الموفين خلال آول عب ساءة بعد العملية وحدوث مضاعفات ما بعد العملية مثل القئ والفثيان.

النتائج والمناقتشة: من خلال الدراسة وجد آن التخدير الموضعى العضلة البطنية المستعرضة إسترشادا بالموجات فوق الصوتية بإستخدام

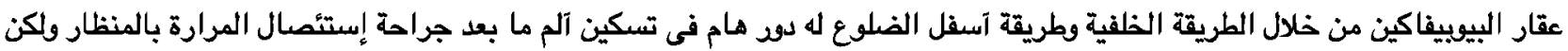

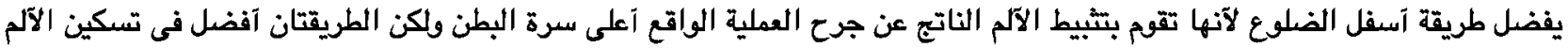

